\title{
Mesenchymal Stem Cell Population Derived from Human Pluripotent Stem Cells Displays Potent Immunomodulatory and Therapeutic Properties
}

\author{
Erin A. Kimbrel, ${ }^{1}$ Nicholas A. Kouris, ${ }^{1}$ Gregory J. Yavanian,, Jianlin Chu, ${ }^{1}$ Yu Qin, ${ }^{2}$ Ann Chan, ${ }^{2}$ \\ Ram P. Singh, ${ }^{3}$ Deborah McCurdy, ${ }^{3}$ Lynn Gordon, ${ }^{2}$ Ralph D. Levinson, ${ }^{2}$ and Robert Lanza ${ }^{1}$
}

Mesenchymal stem cells (MSCs) are being tested in a wide range of human diseases; however, loss of potency and inconsistent quality severely limit their use. To overcome these issues, we have utilized a developmental precursor called the hemangioblast as an intermediate cell type in the derivation of a highly potent and replenishable population of MSCs from human embryonic stem cells (hESCs). This method circumvents the need for labor-intensive hand-picking, scraping, and sorting that other hESC-MSC derivation methods require. Moreover, unlike previous reports on hESC-MSCs, we have systematically evaluated their immunomodulatory properties and in vivo potency. As expected, they dynamically secrete a range of bioactive factors, display enzymatic activity, and suppress T-cell proliferation that is induced by either allogeneic cells or mitogenic stimuli. However, they also display unique immunophenotypic properties, as well as a smaller size and $>30,000-$ fold proliferative capacity than bone marrow-derived MSCs. In addition, this is the first report which demonstrates that hESC-MSCs can inhibit CD83 up-regulation and IL-12p70 secretion from dendritic cells and enhance regulatory T-cell populations induced by interleukin 2 (IL-2). This is also the first report which shows that hESC-MSCs have therapeutic efficacy in two different autoimmune disorder models, including a marked increase in survival of lupus-prone mice and a reduction of symptoms in an autoimmune model of uveitis. Our data suggest that this novel and therapeutically active population of MSCs could overcome many of the obstacles that plague the use of MSCs in regenerative medicine and serve as a scalable alternative to current MSC sources.

\section{Introduction}

$\mathrm{M}$ ESENCHYMAL STEM/STROMAL CELLS (MSCs) are fibroblast-like multipotent cells that can be derived from a variety of adult and fetal tissues [eg, bone marrow (BM), fat, cord blood, etc.] as well as from pluripotent stem cells (PSCs). Currently, there are more than 300 clinical trials evaluating MSC therapeutic utility in a variety of diseases, including osteoarthritis, wound healing, degenerative disc disease, and autoimmune disorders [1]. Unlike other types of cellular therapies, MSCs can be used in allogeneic settings without immunosuppressive therapy due to their ability to evade immune detection [2]. Lack of co-stimulatory molecules such as CD40 and CD80 [2], as well as production of HLA-G, a non-classical MHC class I molecule [3], and expression of serine protease inhibitor 9 [4] may contribute to their immunoprivileged status, although the exact mechanism is not entirely clear.
MSCs home to injured/inflamed tissue and are thought to provide therapeutic support through a multifaceted mechanism. They secrete a dynamic assortment of bioactive cytokines, trophic factors, and anti-inflammatory molecules such as transforming growth factor beta (TGF $\beta)$ [5], monocyte chemotactic protein 1/chemokine (C-C motif) ligand 2 (MCP-1/ CCL2) [6], indoleamine 2,3-dioxygenase (IDO) [7], prostaglandin E2 (PGE2) [8], heme oxygenase-1 (HO-1) [9], monokine induced by gamma interferon (MIG), and interferon gamma (IFN $\gamma$ )-inducible protein 10 (IP-10) [10] in response to environmental cues. In addition to paracrine-acting factors, MSCs use direct cell-to-cell contact $[3,11,12]$ and influence the activities of different immune cell populations [3,13-19]. They may also recruit and/or activate endogenous progenitors to facilitate tissue repair at injury sites [20,21]. Differentiation and long-term engraftment may be another mechanism by which MSCs contribute to tissue repair, yet this is thought to play a relatively minor role in their therapeutic activity [22,23].

\footnotetext{
${ }^{1}$ Advanced Cell Technology, Marlborough, Massachusetts.

${ }^{2}$ Department of Ophthalmology, Jules Stein Eye Institute, David Geffen School of Medicine, UCLA, Los Angeles, California.

${ }^{3}$ Division of Rheumatology, David Geffen School of Medicine, UCLA, Los Angeles, California.
} 
BM has been the most commonly used source for MSCs in both preclinical animal models and clinical trials currently underway. However, differences in quality of donor cells, tissue sources, and culture methods have caused numerous inconsistencies in the reported in vivo effectiveness of MSCs [24-27]. Their limited quantity necessitates in vitro culture and expansion in order to obtain sufficient numbers for clinical use; however, this process may also negatively influence in vivo potency and lead to further inconsistencies [28-31]. The use of human embryonic stem cells (hESCs) or induced PSCs as a source for MSCs may help circumvent many of these issues. Given their pluripotent nature, hESCderived MSCs can be used to generate unlimited amounts of early-passage MSCs of a consistent quality; while donordependent adult tissue sources are non-replenishable, subject to variable quality, and need to be screened for pathogens with every new donor. Moreover, hESC-MSCs can provide corrective functions for diseased, defective, or old MSCs that autologous MSC therapy from a diseased patient cannot provide [32,33].

Since 2005, several groups have reported the derivation of MSCs from PSCs using a variety of methods. These include OP9 co-culture [34,35], embryoid body (EB) formation [36], direct plating of hESCs into MSC media [3739] with cell sorting [40,41], scraping [42], or manual picking and expansion of "raclures," the differentiated areas that spontaneously arise on the edges of hESC colonies $[43,44]$. More recent studies have used inhibitors of TGF $\beta$ and MAPK signaling pathways to augment differentiation of MSCs from hESCs or EBs [45-47]. In vitro characterization shows that hESC-derived MSCs express a host of typical MSC cell surface markers (CD73, CD90, CD105, CD44, etc.) $[38,39,41,48]$, and they have the ability to differentiate into bone, fat, and cartilage [34,37,42], similar to other sources of MSCs. Gene expression profiling has been used to compare hESC-MSCs with those derived from adult BM [34,40] and while some differences exist, the findings suggest that the two types of MSCs are quite similar, supporting the use of hESCs as an alternative source for generating MSCs for clinical use.

While the feasibility of generating hESC-MSCs has been shown with a variety of methods, their ability to sense and respond to environmental cues, to impact immune cell function, and to function therapeutically in vivo have not been explored in as much detail as they have been for BM-MSCs. In this study, we describe a novel and efficient method for generating hESC-MSCs that obviates the need for scraping, sorting, or hand-picking cells and takes advantage of a versatile precursor cell called the hemangioblast to bridge the differentiation process between PSCs and multipotent MSCs. A battery of in vitro and in vivo assays confirms that hESCMSCs have the capacity to respond to environmental cues, influence immune cell function, and exert therapeutic effects which are strong enough to reduce clinical symptoms in two different autoimmune disease models.

\section{Materials and Methods}

\section{hESC culture and differentiation to MSCs}

Human ES cells (MA09, derived from blastomeres, as previously described [49,50]) were cultured in Knockout DMEM, 20\% serum replacement (Gibco, Grand Island, NY),
$10 \mathrm{ng} / \mathrm{mL}$ basic fibroblast growth factor (bFGF), $60 \mu \mathrm{M} \beta$ mercaptoethanol (Sigma-Aldrich, St. Louis, MO), penicillin/ streptomycin, GlutaMAX, and non-essential amino acids and passaged with $0.05 \%$ trypsin-EDTA (Life Technologies, Carlsbad, CA) or in Primate ES Cell Medium (Reprocell, Kanagawa, Japan) $+10 \mathrm{ng} / \mathrm{mL}$ bFGF according to the manufacturer's instructions. hESC cultures were maintained on irradiated mouse embryonic fibroblasts (GlobalStem, Inc., Rockville, MD) or on Matrigel (BD Bioscience, San Jose, CA) by using mTeSR medium (Stem Cell Technologies, Vancouver, Canada). For EB formation, hESCs were plated on low adherence plates (Corning, Corning, NY) in Stemline II (Sigma-Aldrich) plus BMP4 and vascular endothelial growth factor (VEGF) $(50 \mathrm{ng} / \mathrm{mL})$ for 4 days; bFGF $(22.5 \mathrm{ng} / \mathrm{nL})$ was added for the last 2 days. EBs were dissociated with $0.05 \%$ trypsin-EDTA and single cells were replated in Methocult H4536 (Stem Cell Technologies), with $1 \times$ Excyte (Millipore, Billerica, MA), VEGF, Flt3-ligand (FL), thrombopoietin (50 ng/mL each), and bFGF (30 ng/mL) to enable hemangioblast formation, as previously described [51,52]. BMP4 was from Humanzyme (Chicago, IL); all other cytokines in this study were from Peprotech (Rocky Hill, NJ), unless otherwise noted. After 7-12 days, cultures were harvested, rinsed extensively with $1 \times$ Dulbecco's phosphate-buffered saline (PBS) (Life Technologies), and plated as p0 in MSC growth conditions, as described later.

\section{MSC culture and flow cytometry analysis}

hESC-MSCs were grown in MSC growth medium $(\alpha \mathrm{MEM}+16 \%-20 \%$ Hyclone fetal calf serum; ThermoFisher, Waltham, MA) on Matrigel-coated plates until passage 3/4 (p3/4) when matrigel was no longer used. MSCs were passaged using $0.05 \%$ trypsin-EDTA or TrypLE (Life Technologies). For BM-derived MSCs, mononuclear cells were isolated from fresh BM aspirates (AllCells LLC, Alameda, CA) using Histopaque 1077/Accuspin tubes (Sigma-Aldrich) or from frozen human BM mononuclear cells (AllCells LLC) from both male and female donors between 19 and 24 years of age. Mononuclear cells or hemangioblasts were plated at 50,000 cells $/ \mathrm{cm}^{2}$ onto tissue culture plastic in MSC growth medium as p0. Cells at p0 (BM-MSCs or hESC-MSCs) were split when large patches of adherent cells grew; cells from p1 onward were split when $\sim 70 \%-80 \%$ confluence was reached and replated at 4,000-7,000 cells/ $\mathrm{cm}^{2}$. Cell surface markers were analyzed on an Accuri C6 flow cytometer (Accuri Cytometers, Inc., Ann Arbor, MI) according to standard procedures.

\section{Adipogenic differentiation}

hESC-MSCs were seeded in 12-well plates (control: 5,000 cells/well; differentiation: 20,000 cells/well) in MSC growth medium. For the control cells, media were changed every 3-4 days. For differentiation, media were replaced after $24 \mathrm{~h}$ with Complete Adipogenesis Differentiation Medium (STEMPRO Adipogenesis Differentiation Kit; Life Technologies), and cells were cultured for 20 days with feeding every 3-4 days. After 20 days, cells were rinsed with PBS, fixed with $4 \%$ formaldehyde for $30 \mathrm{~min}$ at room temperature (RT), rinsed twice with PBS, and stained with LipidTOX Green (1:100, HCS LipidTOX Neutral Lipid Stains; Life Technologies) for $30 \mathrm{~min}$ at RT. SlowFade Gold 
(SlowFade Gold Antifade Reagent; Life Technologies) was applied, and staining was visualized under a Nikon Eclipse TE2000-S fluorescent microscope $(10 \times)$ using Spot Advanced software (Sterling Heights, MI).

\section{Osteogenic differentiation}

hESC-MSCs were seeded in 12-well plates (control: 5,000 cells/well; differentiation: 20,000 cells/well) in MSC growth medium. For the control cells, media were changed every 3-4 days. For differentiation, media were replaced after $24 \mathrm{~h}$ with Complete Osteogenesis Differentiation Medium (STEMPRO Osteogenesis Differentiation Kit; Life Technologies), and cells were cultured for 34 days with feeding every 3-4 days. After 34 days, cells were rinsed with PBS, fixed with ice-cold $70 \%$ ethanol for $1 \mathrm{~h}$ at RT, rinsed twice with water, stained with $500 \mu \mathrm{L} 20 \mathrm{mg} / \mathrm{mL}$ Alizarin Red (Sigma-Aldrich) for $30 \mathrm{~min}$ at RT, and rinsed again four times with water. Calcium deposits were visualized with bright field microscopy $(10 \times)$.

\section{Chondrogenic differentiation}

$2.5 \times 10^{5} \mathrm{hESC}-\mathrm{MSCs}$ were centrifuged at $500 \mathrm{~g}$ for $5 \mathrm{~min}$ in a $15 \mathrm{~mL}$ conical tube, and pellets were resuspended in $0.5 \mathrm{~mL}$ of chondrogenic medium [high-glucose DMEM, $1 \mathrm{mM}$ Sodium Pyruvate (Life Technologies), $0.1 \mathrm{mM}$ ascorbic acid 2-phosphate (Sigma-Aldrich), $0.1 \mu \mathrm{M}$ dexamethasone (Sigma-Aldrich), 1\% ITS (Collaborative Biomedical Products, Bedford, MA), and $10 \mathrm{ng} / \mathrm{mL}$ TGF 33 ], or MSC culture medium (for controls). Pellet cultures were maintained for 21 days with medium changes every 2-3 days, then fixed with $4 \%$ paraformaldehyde (PFA), and dehydrated in ethanol. Pellets were embedded in paraffin (Mass Histology Service, Inc., Worcester, MA), sectioned, stained with $1 \%$ Alcian Blue 8GX (Sigma-Aldrich), and counterstained with Nuclear Fast Red (Acros Organics, Morris Plains, NJ). Images were taken on an Olympus BX51 microscope with a $40 \times$ UPlanFl $(\mathrm{NA}=0.75)$ objective and stitched with image processing software (Fiji, open source software, http://pacific .mpi-cbg.de/wiki/index.php/Fiji).

\section{Glycosaminoglycan quantification}

Sulfated glycosaminoglycan (sGAG) content was measured using a Blyscan assay (Biocolor Ltd., Carrickfergus, United Kingdom) according to the manufacturer's instructions. Briefly, 2D cultures and 3D pellets were digested with Papain (Sigma-Aldrich) before the addition of Blyscan dye reagent to precipitate the sGAG-dye complex. Samples were evaluated at $656 \mathrm{~nm}$ on a SpectraMax M5 plate reader against a reference standard. DNA concentration was quantified with Hoechst 33258 (Fluorescent DNA Quantitation Kit; BioRad Laboratories, Hercules, CA) using a reference standard. sGAG content was then normalized to DNA content and reported as GAG/DNA $(\mu \mathrm{g} / \mu \mathrm{g})$.

\section{IDO activity}

Cells were stimulated with IFN $\gamma(50 \mathrm{ng} / \mathrm{mL})$ for 3 days, lysed with NP40 lysis buffer (Life Technologies), mixed 1:1 with $2 \times$ IDO buffer (PBS with $40 \mathrm{mM}$ ascorbate, $20 \mu \mathrm{M}$ methylene blue, $200 \mu \mathrm{g} / \mathrm{mL}$ catalase, and $800 \mu \mathrm{M}$ L-tryptophan), and incubated for $30 \mathrm{~min}$ at $37^{\circ} \mathrm{C}$. Reactions were stopped by the addition of $30 \%$ trichloroacetic acid, and incubated for $30 \mathrm{~min}$ at $52^{\circ} \mathrm{C}$. Lysates were then spun down, and supernatants were mixed 1:1 with Ehrlich's reagent (0.8\% p-dimethylaminobenzaldehyde in acetic acid, freshly prepared). After color development, absorbance was read on a spectrophotometer at $492 \mathrm{~nm}$. OD values are compared with a standard of kynurenine for assessing the conversion of tryptophan to kynurenine. Kynurenine concentration was then normalized to 1 million cells. All reagents were from Sigma-Aldrich.

\section{Cytokine secretion}

For most experiments, $17.7 \times 10^{3}$ cells $/ \mathrm{cm}^{2}$ MSCs were plated in six-well plates for $24 \mathrm{~h}$ before stimulation and analyzed with cytometric bead arrays (CBA; BD Bioscience) and ELISAs (ebioscience, San Diego, CA and RayBiotech, Norcross, GA). For PGE2, MSCs were plated at $5 \times 10^{3}$ cells $/ \mathrm{cm}^{2}$ in six-well plates for $24 \mathrm{~h}$ before stimulation. Supernatants were stored at $-20^{\circ} \mathrm{C}$ until assays were performed according to each manufacturer's protocol.

\section{HO-1 intracellular staining}

MSCs were cultured for 3 days in Lab-Tek II Chamber Slides (Nunc). Cell fixation and permeabilization was performed with $4 \%$ PFA at RT for $10 \mathrm{~min}$ and $0.05 \%$ Tween-20 in $1 \% \mathrm{BSA}$ in $1 \times \mathrm{PBS}$ solution, respectively. Anti-human HO-1 antibody (1:100; Novus Biologicals, Littleton, CO) or IgG isotype control (1:100; BD Pharmingen) staining was performed overnight at $4^{\circ} \mathrm{C}$. Cells were washed, counterstained, and mounted with DABCO/DAPI [2.5\% 1,4diazabicyclo[2.2.2] octane (Sigma-Aldrich), 50\% glycerol (Fisher Scientific, Forest Lawn, NJ), and 0.005\% 4',6diamidino-2-phenylindole (Sigma-Aldrich) in PBS)], and fluorescent images were acquired with a $20 \times$ UplanFluor objective $(\mathrm{NA}=0.45)$ on a Nikon Eclipse TE2000-S microscope and analyzed with Fiji open source software.

\section{Dendritic cell maturation and MLR analyses}

Dendritic cells (DCs) were derived from peripheral blood mononuclear cells (PBMCs) by a $24 \mathrm{~h}$ selective adherence of monocytes followed by culturing adherent cells in Lympho Medium: IMDM $+10 \%$ heat-inactivated fetal calf serum containing granulocyte macrophage colony-stimulating factor (GM-CSF) and interleukin 4 (IL-4), as has been routinely used (reviewed in Refs. [53,54]), plus stem cell factor, FL, and interleukin 3 (IL-3). Flow cytometry for CD11c, CD209, HLA-ABC, HLA-DR, and CD40 confirmed that $>90 \%$ of cells were DCs after 4 days of incubation in Lympho Medium. DCs were co-cultured with MSCs in Lympho Medium for 2 additional days; then, $100 \mathrm{ng} / \mathrm{mL}$ LPS $+20 \mathrm{ng} / \mathrm{mL}$ IFN $\gamma$ was added for $18 \mathrm{~h}$ to induce DC maturation (similar to Ref. [13]). Cells were subjected to flow cytometry for CD83 expression or conditioned medium (CM) was used for IL12p70 ELISA (ebioscience) according to the manufacturer's protocol. In the "two-way" mixed leukocyte reaction (MLR), hESC-derived MSCs were used as inhibitors and DCs were used as stimulators. Non-adherent PBMCs [labeled with carboxyfluorescein succinimidyl ester (CFSE)] were used as responders. In some experiments, responders were tracked with BrdU labeling instead of CFSE. MSCs and 
DCs were mitotically inactivated with $5-10 \mu \mathrm{g} / \mathrm{mL}$ Mitomycin C (Sigma-Aldrich) before MLR co-culture. DCs were allogeneic to PBMC responders. Proliferation of responders was measured with flow cytometry for CFSE decay, CD4, and CD8 or by BrdU intracellular flow along with CD4 and CD8a, according to the manufacturer's instructions (BD Bioscience).

\section{Animal models}

For lupus nephritis (LN), 24-week-old lupus-prone $(\mathrm{NZB} \times \mathrm{NZW}) \mathrm{BWF} 1$ female mice were intravenously injected with $100 \mu \mathrm{L}$ of PBS only, 2 million hESC-MSCs in PBS, or 2 doses of $0.5 \times 10^{6} \mathrm{hESC}-\mathrm{MSC}$ in PBS separated by a 2 week interval ( $n=10$ per group). Mice received no other treatment, and survival was monitored for 70 days post-MSC injection and plotted on a Kaplan-Meier graph. Mice were from Jackson Labs (Bar Harbor, ME). For the first experimental autoimmune uveitis (EAU) experiment, 7-9-week-old C57BL/6 female mice were immunized with $500 \mu \mathrm{g}$ of the uveitogenic peptide (amino acids 1-20) from the interphotoreceptor retinoid-binding protein (IRBP) and $1.5 \mu \mathrm{g}$ pertussis toxin on day 0 to induce mild uveitis. hESCMSCs $\left(5 \times 10^{6} / \mathrm{mouse}\right)$ were intraperitoneally injected on day 0 . On day 21 , fundoscope imaging and clinical evaluation was performed in a blinded fashion by two independent clinicians. Clinical exam scores are based on a scale of $0-4$, as previously described [55], with higher numbers being more severe in terms of inflammation and tissue damage. Mice were then sacrificed; eyes were harvested and fixed with $4 \%$ glutaraldehyde for $1 \mathrm{~h}$ and then $10 \%$ formaldehyde for $18 \mathrm{~h}$; paraffin embedded; and sectioned for hematoxylin-eosin (H\&E) staining. For the second EAU experiment, 7-8-weekold B10RIII female mice were immunized with $100 \mu \mathrm{g}$ IRBP (aa161-180) peptide $+1.5 \mu \mathrm{g}$ pertussis toxin on day 0 . On day 7 post-immunization, $5 \times 10^{6} \mathrm{hESC}-\mathrm{MSCs}$ were intraperitoneally injected per mouse and mice were sacrificed on day 14 for histology as described earlier. H\&E images were captured on an Olympus BX51 microscope.

\section{Statistical analysis}

Two-tailed Student's $t$-tests were used to determine $P$-values for significance, where indicated.

\section{Results}

In order to evaluate the utility of hemangioblasts for generating MSCs, we differentiated pluripotent MA09 hESCs into EBs for 4 days followed by several days of growth in a cytokine-rich, serum-free, methylcellulose-based medium as previously described [51]. Within 3-4 days in the methylcellulose medium, clusters of shiny, spherical cells (hemangioblasts) began emerging and expanded rapidly over the course of several days, as previously described [51,52] (Fig. 1A). Within 9-10 days, hemangioblast cultures routinely expanded anywhere from 3- to 22-fold over the input EB cells (Fig. 1B). Hemangioblasts were then plated onto matrigel-coated plates in $\alpha \mathrm{MEM}+20 \%$ FCS to enable differentiation into passage 0 MSCs. Within 5 days, patches of adherent fibroblast-like cells began emerging and represented about $15 \%-20 \%$ of the input cells. Adherent cells were har- vested and replated for continued differentiation into passage 1 MSCs, while non-adherent cells were discarded. From p1 onward, cells were routinely passaged when cultures became $\sim 70 \%-80 \%$ confluent. A flow cytometric comparison between hemangioblasts and the resulting MSCs highlights the differences in their immunophenotype and the generation of hESC-derived MSCs with characteristic MSC cell surface markers (Fig. 1C). While 0\%-10\% of hemangioblasts are positive for CD90, CD105, or CD73, $\geq 95 \%$ of MSCS are positive for these markers. In addition, $80 \%$ of hemangioblasts are positive for the hematopoietic marker CD45, while MSCs are negative. We also tested the trilineage differentiation potential of our hESC-MSCs and found that they were able to differentiate into lipid-containing adipocytes, calciumcontaining osteocytes, and GAG-containing chondrocytes (Fig. 1D-G). Thus, our hESC-MSCs met the minimal ISCT criteria to define them as MSCs [56].

To further characterize our hESC-MSCs, we wanted to compare them against those derived from adult tissue. Since adult BM is arguably the most widely used source, we isolated BM-MSCs from several different donors and compared their population doublings, cell size, and cell surface markers with those of our hESC-MSCs. As shown in Figure 2A, we found that hESC-MSCs had a higher proliferation index than BM-MSCs; they underwent twice as many population doublings (for a 30,000-fold greater expansion) than BM-MSCs in just more than 2 months' time. We also noted that their size tended to be smaller than BMMSCs at the same passage (Fig. 2B and Supplementary Fig. S2A; Supplementary Data are available online at www .liebertpub.com/scd). Interestingly, both hESC-MSCs and BM-MSCs became larger as they aged and were serially passaged, yet the change in size was greater for BM-MSCs than it was for hESC-MSCs (Supplementary Fig. S2B). The immunophenotype of hESC-MSCs was quite similar to that of BM-MSCs (Fig. 2C), with a few exceptions. Less than $1 \%$ of hESC-MSCs were Stro-1 positive, while approximately $25 \%$ of BM-MSCs were positive for this marker. In addition, $\sim 25 \%$ of hESC-MSCs were CD10 ${ }^{+}$and $\sim 18 \%$ were $\mathrm{CD} 24^{+}$, while these two markers failed to appear in more than $1 \%-2 \%$ of BM-MSCs (Fig. 2C, D). Quantitative RT-PCR (qRT-PCR) confirmed these results (Supplementary Fig. S2C). Interestingly, CD24 expression was highest in early-passage hESC-MSCs and declined as cells were successively passaged (Supplementary Fig. S2C, last graph).

MSCs are known to secrete a panoply of cytokines and growth factors, some of which change in response to local environmental cues, and these factors are thought to alter the behavior of local immune cells and/or enhance tissue repair. We evaluated the ability of hESC-MSCs to respond to the proinflammatory cytokines IFN $\gamma$, tumor necrosis factor alpha $(\mathrm{TNF} \alpha)$, or both by changes in their secreted factors. After a 48-h stimulation, we subjected MSC CM to CBA and ELISA (Fig. 3). The secreted factors, IP-10 and MIG showed some responsiveness to IFN $\gamma$ stimulation but were strongly up-regulated in response to the combination of IFN $\gamma$ and $\mathrm{TNF} \alpha$ (first two graphs). Interleukin 6 (IL-6) was up-regulated to varying degrees in response to all three stimuli used. IL-8, MCP-1, and CCL5/RANTES (regulated on activation, normal $\mathrm{T}$ cell expressed and secreted) were not stimulated at all by IFN $\gamma$ alone but were responsive to $\mathrm{TNF} \alpha$ and the combination of $\mathrm{TNF} \alpha$ and IFN $\gamma$. GM-CSF 

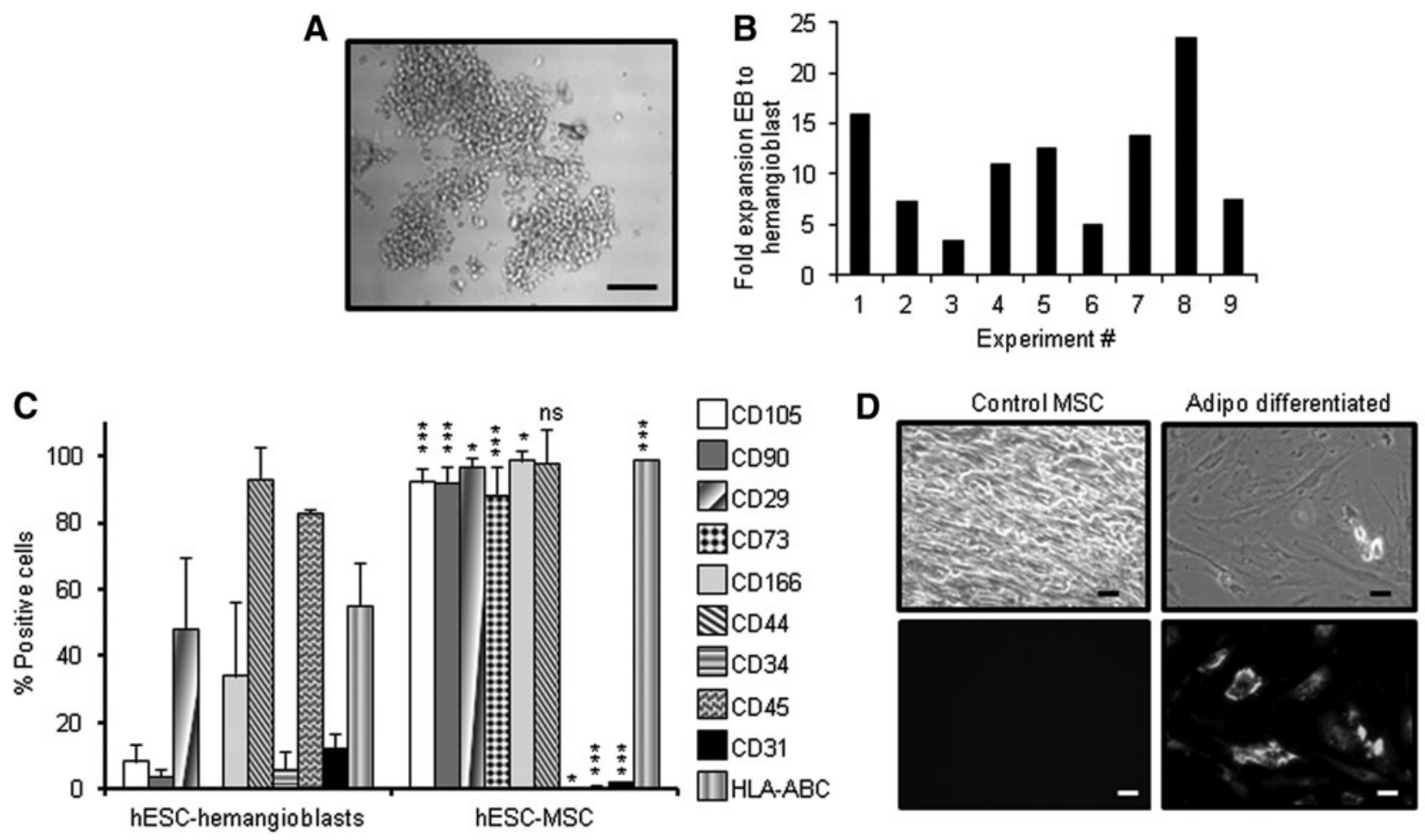

E

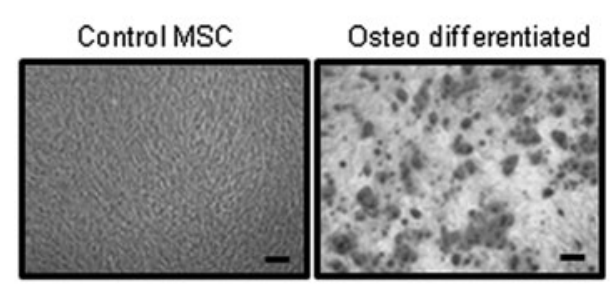

$\mathbf{F}$

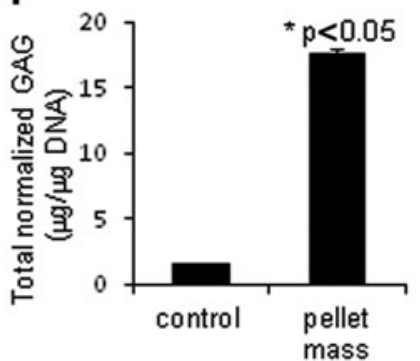

G

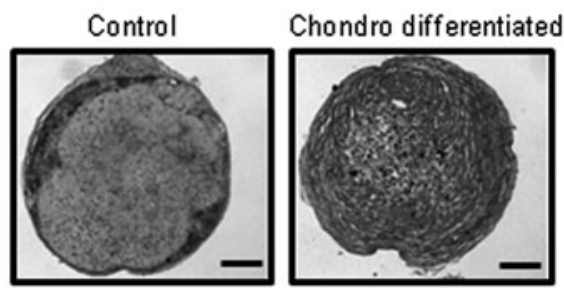

FIG. 1. Generation of human embryonic stem cell (hESC)-mesenchymal stem cells (MSCs) using a hemangioblast intermediate step. (A) Grape-like clusters of hESC-derived hemangioblasts at day $9(20 \times)$. (B) Bar graph showing fold expansion of cells through day 9 (experiment \#1-6) or day 10 (\#7-9) of hemangioblast culture. (C) Bar graph showing summary of flow cytometry data for hemangioblasts and hESC-MSCs. After gating for size, then lack of propidium iodide staining, the $\%$ of viable cells staining positive for each marker is indicated on the $y$-axis. Bars represent average, and error bars represent standard deviation, $n=4$ for each marker, each cell type (hemangioblast vs. MSC, ns, not significant; * $P \leq 0.02$; ** $P \leq 0.002$; $* * * P \leq 0.0002)$. Representative histograms are shown in Supplementary Figure S1. (D) Adipogenic differentiation of MSCs. Left panels are undifferentiated control MSCs, and right panels are MSCs that have been differentiated toward adipocytes. Top row is phase contrast, and bottom row is staining with LipidTox. Images at $10 \times$. (E) Osteogenic differentiation of MSCs. Left panel shows undifferentiated control MSCs, right panel shows MSCs that have been differentiated toward osteocytes, images at $10 \times$. Cells in both panels were stained with Alizarin Red. (F, G) Chondrogenic differentiation of MSCs. (F) Glycosaminoglycan content (normalized to DNA content) of control MSCs versus MSCs in pellet culture. Bars represent the average of three experiments, and error bars are standard deviation. (G) Alcian Blue staining of pellet mass cultures for undifferentiated control MSCs (left panel) versus MSCs that have been differentiated toward chondrocytes (right panel). Scale bars $=100 \mu \mathrm{m}$.

was up-regulated specifically in response to $\mathrm{TNF} \alpha$, but not when used in combination with IFN $\gamma$. Lastly, TGF $\beta$, while detectable, was constitutively expressed and appeared to be slightly down-regulated in response to the combination of IFN $\gamma$ and $\mathrm{TNF} \alpha$. Other cytokines and chemokines such as IL-4, M-CSF, IL-10, hepatocyte growth factor (HGF), VEGF, insulin-like growth factor 1 (IGF1), placenta growth factor (PIGF), bFGF, and stromal cell-derived factor 1 (SDF-1) were tested via a combination of CBA, ELISA, cytokine antibody arrays, and/or qRT-PCR but were not consistently detected or only at negligible levels (Supplementary Fig. S3A-C, and data not shown). Angiopoietin 1; brain-derived neurotrophic factor were tested by cytokine antibody arrays only, however their levels were consistently low and did not change much after stimulation (Supplementary Fig. S3A, B). We also evaluated the ability of hESCMSCs to produce exosomes, which are microvesicles that are used to package secreted proteins, RNA, and miRNA. We 
A

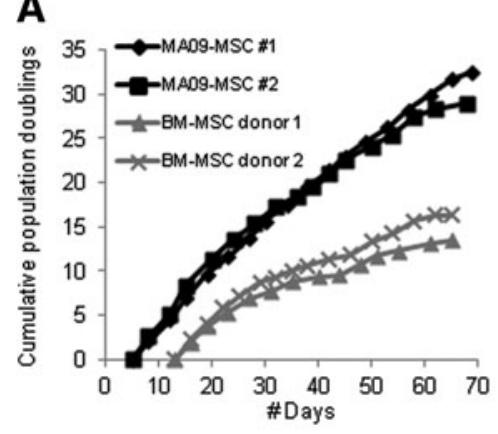

C

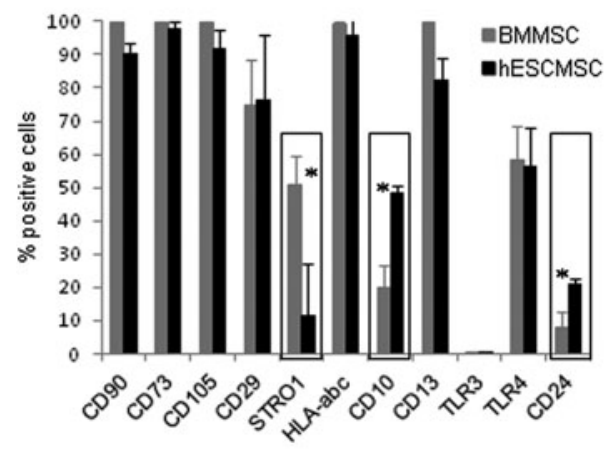

B

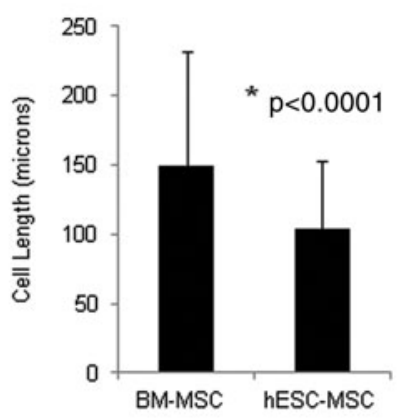

D
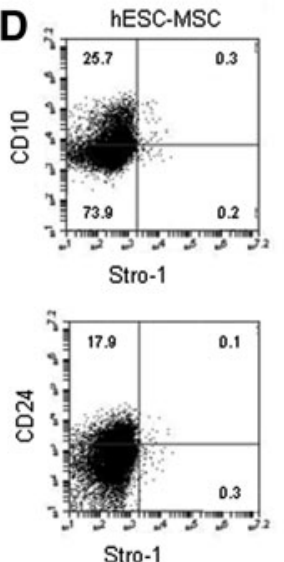

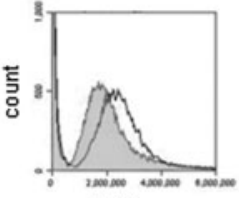

FSC
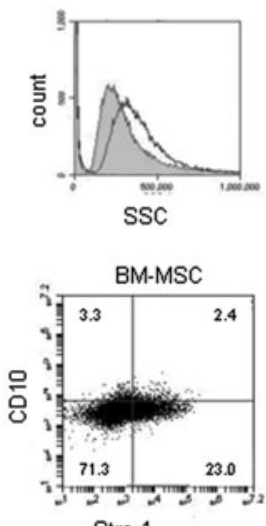

Stro-1

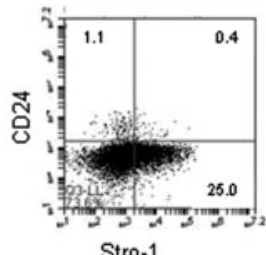

FIG. 2. Comparison of hESC-MSCs to bone marrow (BM)-MSCs shows some similarities and some differences. (A) Cumulative population doublings (PD) over time for two hESC-MSC lines (black lines with diamonds and squares) versus two BM-MSC lines from different donors (gray lines with triangles and $X s$ ), starting at passage 0 . On harvest, cells were counted, replated at 6,800 cells $/ \mathrm{cm}^{2}$ for subsequent passages. Cumulative PD were calculated based on $\mathrm{PD}=\log (\mathrm{Nf}-\mathrm{Ni}) /$ $\log 2$, by which Nf is number of harvested cells and Ni is number of cells initially plated. (B) Left panel: bar graph showing statistically significant difference in average cell length for BM-MSCs $(n=118)$ and hESC-MSCs $(n=105)$ at passage 5, $P<0.0001$ using two-tailed Student's $t$-test. Right panel contains histogram plots showing the slight size difference in FSC (top graph) and SSC (bottom graph) between hESC-MSCs and BM-MSCs at p5. hESC-MSCs are in shaded gray, and BMMSCs are in shown with unshaded black line. (C) Bar graph showing percentage of MSCs staining positive for indicated cell surface markers using flow cytometry for hESC-MSCs and BM-MSCs. Bars represent average of three to six experiments, and error bars represent standard deviation. Boxes are drawn around markers with significant differences between hESC-MSCs and BM-MSCs (corresponding histogram plots are shown in Supplementary Fig. S1). *Indicates statistically significant $P$-values $(P<0.005$ for Stro-1; $P<0.002$ for CD10, and $P<0.02$ for CD24). (D) Representative flow cytometry dot plots for hESC-MSCs and BM-MSCs for CD10, Stro-1, and CD24.

followed a standard ultracentrifugation isolation procedure followed by CD63 gold immunolabeling [57] to visualize exosomes under transmission electron microscopy. Spherical vesicles of 50-75 $\mu \mathrm{m}$ in diameter were observed and positively labeled with CD63 (Supplementary Fig. S3D). These observations confirmed that the hESC-MSCs produce exosomes as a part of their secretory program.

In addition to secreting immunomodulatory cytokines, MSCs are thought to influence immune cells through the actions of HO-1, IDO, and PGE2 among other factors. Heme oxygenases are enzymes that are involved in the normal breakdown of red blood cells; they catalyze the degradation of heme into biliverdin. HO-1 is an inducible form that is involved in countering oxidative damage and inflammation [58]. We found that hESC-MSCs express HO-1 constitutively; it is readily detectable in the basal state (Fig. 4A) and does not increase in response to IFN $\gamma$ or $\mathrm{TNF} \alpha$ stimulation (data not shown). IDO enzymatically converts tryptophan to kynurenine, and this process is thought to deplete local tryptophan pools, thus hindering T-cell proliferation [59]. hESC-MSCs do not display IDO enzymatic activity in the basal state, yet they showed a robust induction of IDO enzymatic activity in response to IFN $\gamma$ stimulation, (Fig. $4 \mathrm{~B})$. We observed that IDO gene expression is also strongly up-regulated in response to co-culture with mitogen-activated PBMCs (Supplementary Fig. S3E). PGE2 is an eicosanoid molecule that is produced through multi-step metabolism of arachidonic acid and is thought to play a role in the antiinflammatory and immunomodulatory effects of MSCs, including the inhibition of DC maturation [8]. We found that PGE2 secretion from hESC-MSCs is strongly up-regulated in response to costimulation with IFN $\gamma$ and TNF $\alpha$. Collectively, these data demonstrate that our hESC-MSCs produce a variety of bioactive proteins and they can respond to local environmental cues in a manner which is consistent with what has been reported for adult tissue-derived MSCs [60]. 

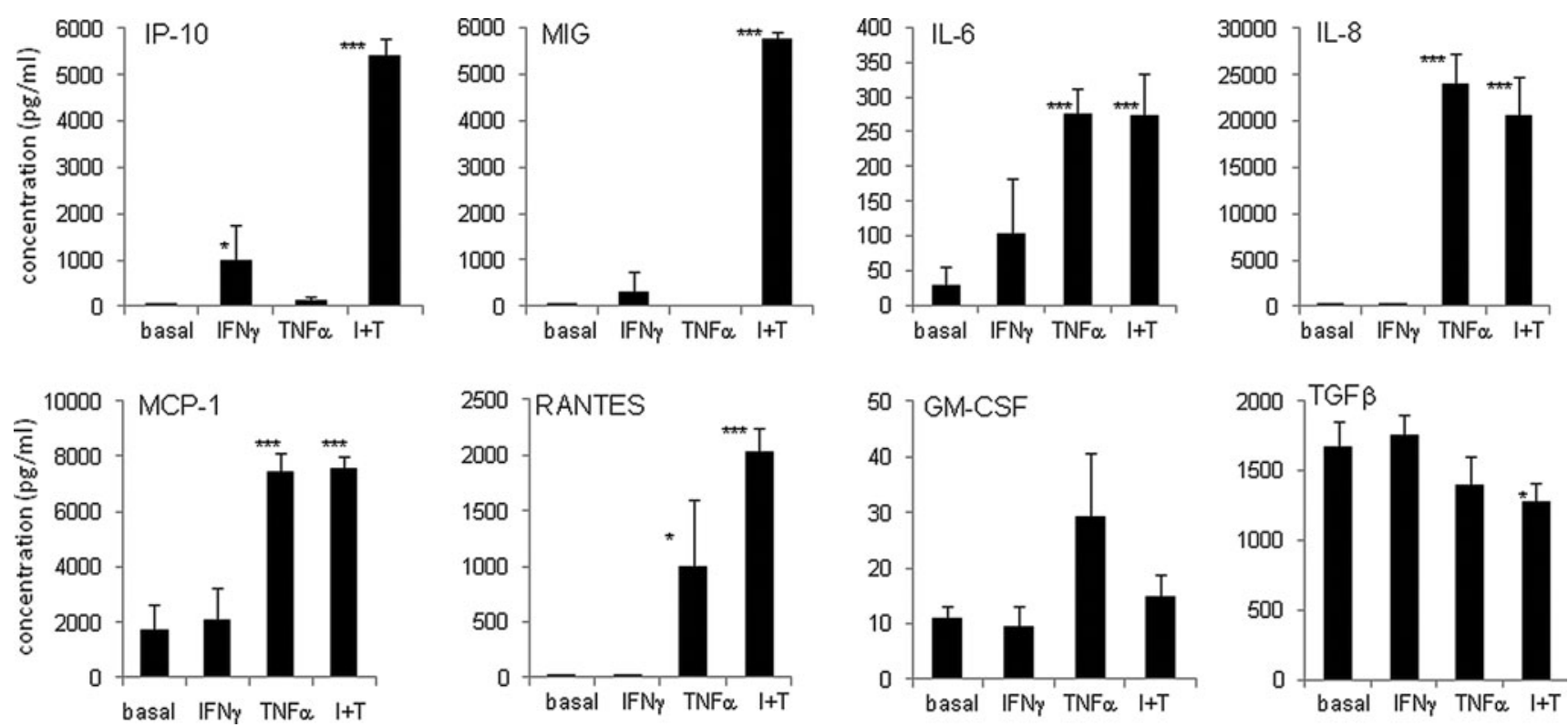

FIG. 3. Dynamic changes in secreted proteins in response to pro-inflammatory stimulation. Quantitative assessment of cytokine concentration in hESC-MSC conditioned medium (CM) in the absence or presence of $50 \mathrm{ng} / \mathrm{mL}$ interferon gamma (IFN $\gamma$ ) and/or $25 \mathrm{ng} / \mathrm{mL}$ tumor necrosis factor alpha (TNF $\alpha)$ as indicated for $48 \mathrm{~h}$. Human chemokine cytometric bead arrays (BD Bioscience) were used for inducible protein 10 (IP-10), monokine induced by gamma interferon (MIG), interleukin 8 (IL-8), monocyte chemotactic protein 1 (MCP-1), and RANTES; while ELISAs (ebioscience) were used for IL-6, granulocyte macrophage colony-stimulating factor (GM-CSF), and transforming growth factor beta (TGF $\beta$ ), according to the manufacturer's protocols. Media only was used to determine background in all assays. Bars show the average of three to five independent experiments for each cytokine; error bars are SD; $P$-values for significance between basal and stimulated (IFN $\gamma, \mathrm{TNF} \alpha$, or IFN $\gamma+\mathrm{TNF} \alpha)$ states, $* P \leq 0.02 ; * * P \leq 0.002 ; * * * P \leq 0.0002$.

hESC-MSCs, equipped with an immunomodulatory arsenal, should be able to affect the activity of both innate and adaptive immune cells directly. To test this, we generated immature DCs from PBMC monocytes using a medium containing GM-CSF and IL-4. Flow cytometry confirmed expression of CD11c, CD209, HLA-DR, and CD40 on $\geq 95 \%$ of cells after 4 days of differentiation (Supplementary Fig. S4A-C). CD11c versus CD73 staining could also be used to distinguish DCs from MSCs in co-culture (Supplementary Fig. S4C, D). In the absence of MSCs, DCs strongly up-regulated both $\mathrm{CD} 83$ expression (Fig. 5A) and IL-12p70 secretion (Fig. 5B) in response to a LPS/IFN $\gamma$ maturation cocktail; however, co-culture with MSCs caused a reduction in the inducible CD83 and IL-12p70 expression on exposure to maturation cocktail. We next tested the ability of hESC-MSCs to interfere with T-cell proliferation in response to different stimuli by using MLRs assays. Nonadherent PBMCs were used as responders, allogeneic immature DCs were used as stimulators, and MSCs were used as third-party effectors. In response to increasing amounts of DCs, the $\mathrm{CD}^{+}$and/or $\mathrm{CD} 8^{+}$T-cell population within the PBMCs proliferated in a DC dose-dependent manner, as assessed by BrdU staining (Fig. 5C, gray line with squares). When a fixed amount of MSCs were added to the MLR, they inhibited the DC-induced T-cell proliferation (Fig. 5C, black line with diamonds and Supplementary Fig. S5). When a constant amount of allogeneic DC was used as stimulation, increasing amounts of MSCs inhibited T-cell proliferation in a dose-dependent manner (Fig. 5D and Supplementary Fig. S6). Likewise, when PMA and ionomycin were used as a mitogenic stimulus, increasing amounts of MSCs also inhibited T-cell proliferation in a dose-dependent manner (Supplementary Fig. S7). MSCs were also observed to enhance the $\mathrm{CD}^{+}{ }^{+}$/ $\mathrm{CD} 25^{+} / \mathrm{FoxP}^{+}$regulatory $\mathrm{T}$-cell population in response to IL-2 stimulation of PBMCs (Supplementary Fig. S8). These data show that hESC-MSCs are able to impact both innate and adaptive immune cells in response to different stimuli.

The true litmus test for MSC clinical potential is an in vivo demonstration of efficacy in combating disease. We used two different autoimmune disease mouse models to examine hESC-MSC therapeutic utility: LN and EAU. LN spontaneously arises in BWF1 mice ( $\mathrm{F} 1$ offspring from NZW $\times$ NZB cross), beginning at around 20-24 weeks of age [61] and resulting in a reduced lifespan (50\% mortality by $\sim 35$ weeks) due to kidney dysfunction [62] (Fig. 6A, black line with diamonds). We found that the administration of hESC-MSCs, as either a single injection (Fig. 6A, black line with squares) or two injections given 2 weeks apart (Fig. 6A, gray line with triangles), significantly prolonged the lifespan of BWF1 mice. Further investigation into the mechanism(s) underlying MSC therapeutic effects is an active area of investigation. EAU is an inflammatory eye disorder of the uvea, which can be induced in mice by immunizing with peptides from the retinal protein, IRBP [63]. We induced mild uveitis in C57BL/6 mice and assessed disease severity in a blinded fashion using both in vivo fundoscopic imaging and histopathology. Both of these examinations are scored on standard scales of $0-4$, with the higher number indicating more severe phenotype [55]. EAU mice that received hESC-MSCs had significantly lower 
A

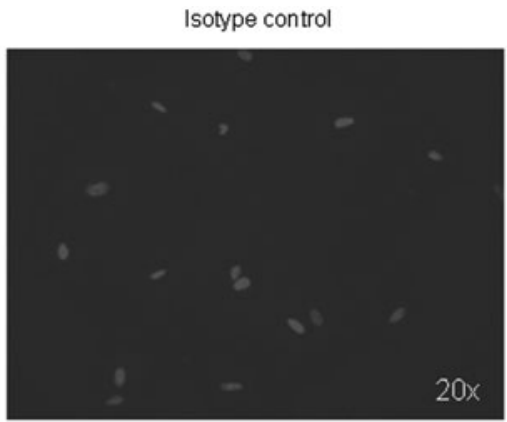

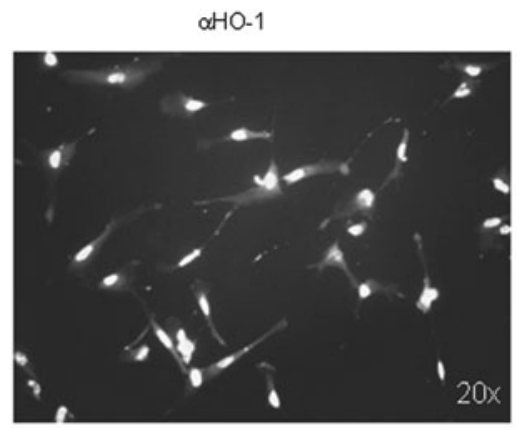

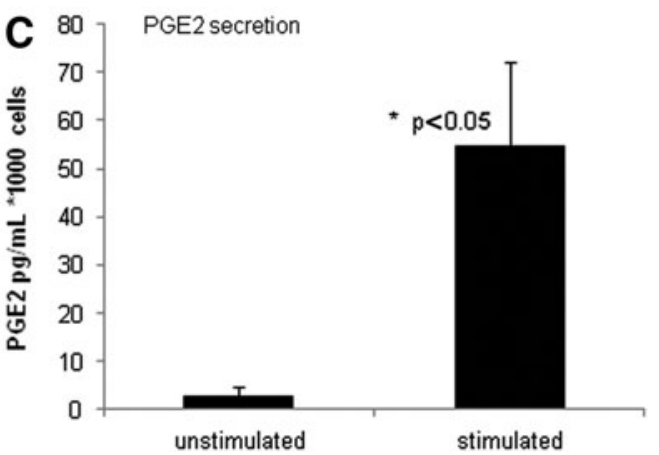

FIG. 4. Signaling molecules produced by hESC-MSCs. (A) Immunofluorescence of MSCs stained with isotype controlFITC (left panel) or anti-HO-1-FITC antibody (right panel) and costained with DAPI. Images at $20 \times$. (B) Normalized indoleamine 2,3-dioxygenase (IDO) enzymatic activity in unstimulated hESC-MSCs versus MSCs stimulated with $50 \mathrm{ng} /$ $\mathrm{mL}$ IFN $\gamma$ for 3 days. Kynurenine concentration per million cells reflects the conversion of tryptophan to kynurenine by IDO enzyme. Bars show the average of 13 experiments \pm SD. (C) Prostaglandin E2 (PGE2) secreted by unstimulated MSCs or MSCs that have been stimulated with $50 \mathrm{ng} / \mathrm{mL}$ IFN $\gamma$ and $25 \mathrm{ng} / \mathrm{mL}$ TNF $\alpha$ for 3 days. Amount of PGE2 (pg/mL) is normalized per 1,000 cells, $n=3$ independent experiments \pm SD.

disease scores than EAU mice which did not receive hESCMSCs (Fig. 6B, C). In addition, we injected MSCs into C57BL/6 mice that were not induced with EAU and found no evidence of histologic changes in eyes, brain, lungs, spleen, and GI tract (data not shown). In a pilot study of more severe EAU performed in B10RIII mice, a single injection of hESC-MSCs markedly reduced disease severity as well. Histologic eye images of B10RIII EAU mice that did not receive any hESC-MSCs show heavy inflammatory cell infiltrates in the vitreous cavity, multiple retinal folds and detachment, inflammatory cell infiltration with disruption of the outer retina, and subretinal neovascularization (Fig. 6D left panel). In comparison, EAU mice treated with hESCMSCs (Fig. 6E, right panel) show far fewer inflammatory cell infiltrates in the vitreous space, reduced retinal folds, and less tissue damage. A more detailed study is underway to probe the mechanisms underlying the ability of hESC-MSCs to reduce clinical features of EAU. Together, the LN and EAU data provide proof of principle that our hESC-MSCs have therapeutic utility against autoimmune disorders.

\section{Discussion}

Several different methods have been used to generate MSCs from PSCs, yet their immunomodulatory properties and in vivo therapeutic potential have not been nearly as well characterized as those of BM-MSCs. We describe here the use of hemangioblasts as an intermediate cell type to bridge the differentiation process between hESCs and
MSCs. While extremely transient during development, hemangioblasts can be generated $[51,64,65]$ and easily expanded from hESCs in vitro [52]. Their potential as an endothelial/hematopoietic precursor has proved to be quite useful for generating vascular endothelium and smooth muscle [51,66,67], red blood cells [68], platelets [69], DCs (our own unpublished data), and now MSCs. The use of a hemangioblast intermediate helps push the initial differentiation of hESCs in a more directed fashion than the stochastic differentiation involved in exclusively using EBs. It also provides an opportunity to expand the pool of progenitors that may give rise to MSCs before further differentiation, a property which is important when one considers that not all hESCs will turn into MSCs. Moreover, going through a hemangioblast intermediate also helps avoid possible carry-over of residual pluripotent cells, a risk that direct plating methods cannot easily avoid but which is an important consideration for any cellular therapy derived from hESCs.

In surveying the properties of our hESC-MSCs that may give them therapeutic potential, we found that they produce a dynamic array of cytokines, chemokines, and growth factors, including IL-10, CCL2, and GM-CSF, MIG, IP-10, HO-1, IDO, and PGE2, many of which change depending on signals in the environment. These factors are overlapping with those secreted by adult tissue-derived MSCs $[6,8,70]$, cord-blood-derived MSCs [71], and other hESC-MSCs [72]. It is likely that the combination of many secreted factors contribute to MSC therapeutic effects in different in vivo 
A

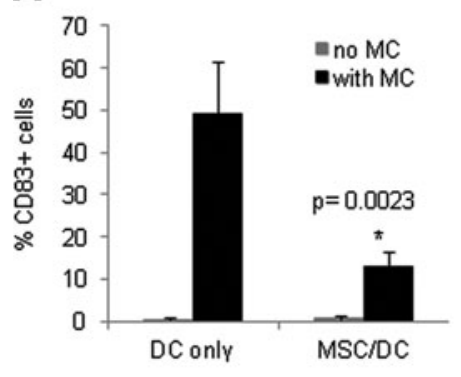

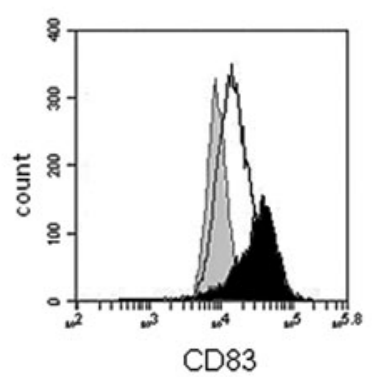

B
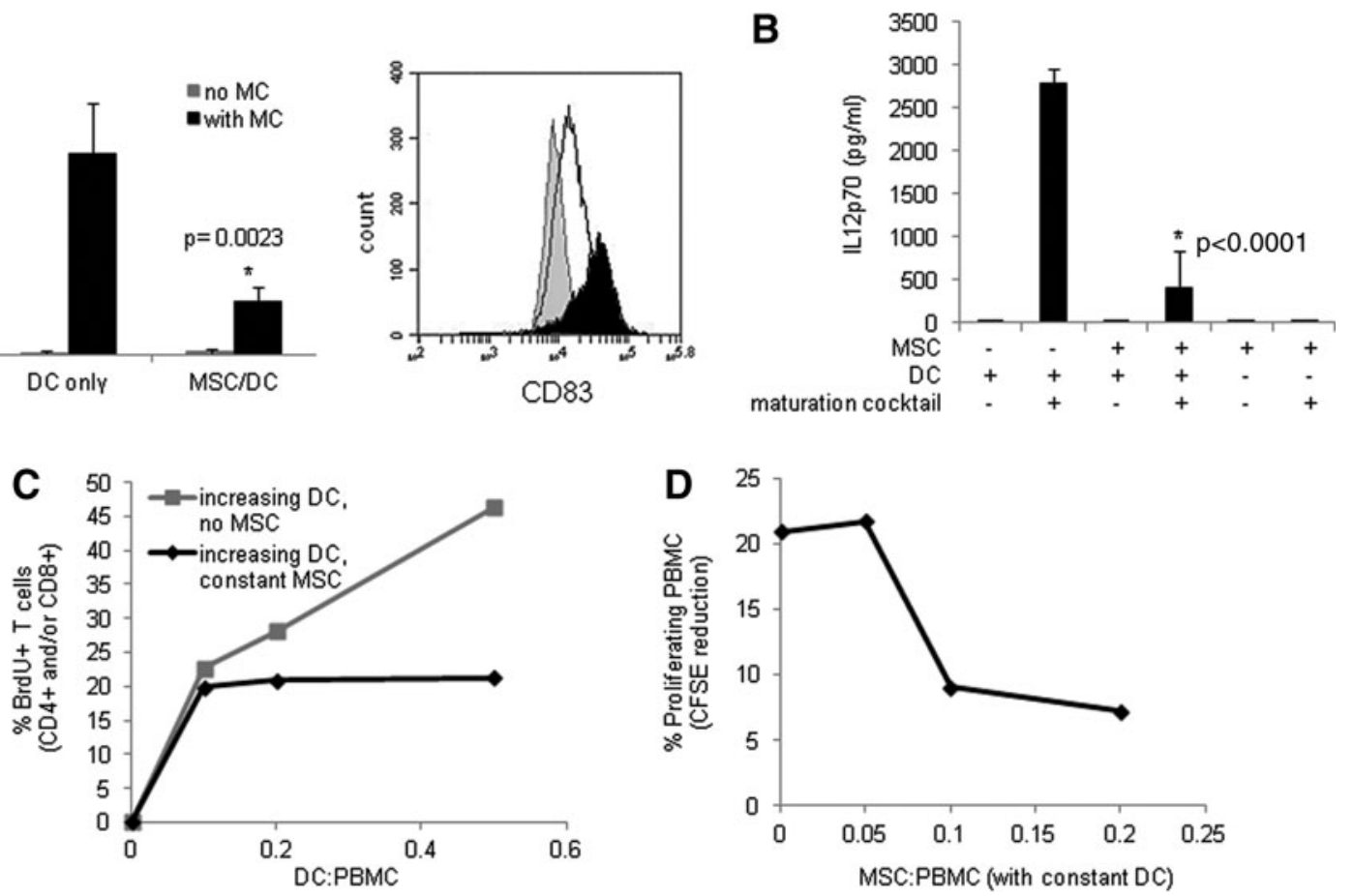

FIG. 5. Immunomodulatory activity of hESC-MSCs on cells of innate and adaptive immune system. (A, B) Effects of hESC-MSC co-culture on dendritic cell (DC) maturation due to the addition of $20 \mathrm{ng} / \mathrm{mL} \mathrm{IFN} \gamma$ and $100 \mathrm{ng} / \mathrm{mL}$ LPS (=maturation cocktail, "MC") for $18 \mathrm{~h}$. (A) Flow cytometry for CD83 up-regulation on DCs, with DCs alone or in coculture with MSCs at a ratio of 5:1 (DC:MSC). Bars represent the average of four experiments, error bars are SD, $P<0.005$ between "DC only with MC," and "MSC/DC with MC." Histogram plot shows CD83 expression on CD11c ${ }^{+}$DCS, alone without maturation (shaded in gray), DC alone with maturation (shaded in black), and DCs in co-culture with MSCs with maturation (black line unshaded). (B) IL-12p70 concentration (pg/mL) in CM from indicated cultures, $\pm \mathrm{MC}$ as determined by ELISA, and IL-12p70 standard curve, $n=4$ independent experiments with DC:MSC co-culture ratio of 4:1, $P<0.0001$ between "DC only + MC" and "MSC/DC+MC." (C) Mixed leukocyte reaction (MLR) assay using increasing amounts of allogeneic DCs to stimulate proliferation of peripheral blood mononuclear cell (PBMC) responders and the effects of MSCs as third-party cells. $\mathrm{x}$-Axis shows the increasing ratio of allogeneic DC:PBMC in the MLR cultures. BrdU ${ }^{+}$incorporation is used to assess proliferation of $\mathrm{CD}^{+}$and/or $\mathrm{CD}^{+}{ }^{+} \mathrm{T}$ cells within the PBMC responder pool in the absence of third-party MSCs (gray line with squares) or the presence of a constant amount of MSCs (black line with diamonds). (D) MLR assay using a constant amount of allogeneic DCs to stimulate proliferation of carboxyfluorescein succinimidyl ester (CFSE)labeled PBMCs and the effects of increasing amounts of MSCs. Proliferation was assessed by the reduction in CFSE signal by day 5 of the MLR. First point on the plot shows the level of DC-induced PBMC proliferation without any MSCs, and the next three points are with increasing amounts of third-party MSCs in the MLR culture.

environments. Adult tissue-derived MSCs have been shown to inhibit DC differentiation and maturation [13,14], yet this study is the first to examine the effects of hESC-derived MSCs on DCs. Our hESC-MSCs suppressed CD83 expression and IL-12p70 secretion, both of which are involved in the DC maturation/activation process and integral to the ability of DCs to properly deliver signals to T cells [73]. This is also the first study which shows that hESC-MSCs can enhance regulatory T-cell populations in response to IL2, similar to what has been reported for BM-MSCs [17]. Three other groups which have generated hESC-MSCs reported that their cells inhibited T-cell proliferation in MLR assays $[38,41,44]$ as did ours in response to both allogeneic DCs and mitogenic stimuli. However, a fourth group found that their hESC-MSCs did not inhibit T-cell proliferation in MLR assays [48]. Obviously, differences in the starting hESC lines and MSC derivation methods may affect the quality and properties of the resulting cells. It may be interesting to do a side-by-side comparison of immunomodulatory properties for hESC-MSCs derived with different methods. Nonetheless, our hESC-MSCs displayed a range of features and functions similar to those reported for BMMSCs and considered important for MSC medicinal effects.

Despite many similarities to BM-MSCs, we identified some differences as well. We observed that approximately $25 \%$ of BM-MSCs expressed Stro-1, yet few, if any, hESCMSCs expressed it. One study suggests that Stro-1 expression is indicative of the starting tissue, with it being expressed in MSCs derived from BM but not in those derived from adipose [74]. However, another study finds that Stro-1 is important for a high proliferative rate of mesenchymal progenitors from BM [75]. We found a high proliferative rate of our MSCs without Stro-1 expression, thus underscoring the possibility that other markers or properties, perhaps particular to individual tissue sources, can have similar functional consequences as Stro-1 may have for BM. We found that both CD10 and CD24 expression was greater in $\mathrm{hESC}-\mathrm{MSC}$ populations than in BM-MSCs. Interestingly, when cells were grown in commercially available, serumfree media instead of standard aMEM $+20 \%$ FCS, CD10 

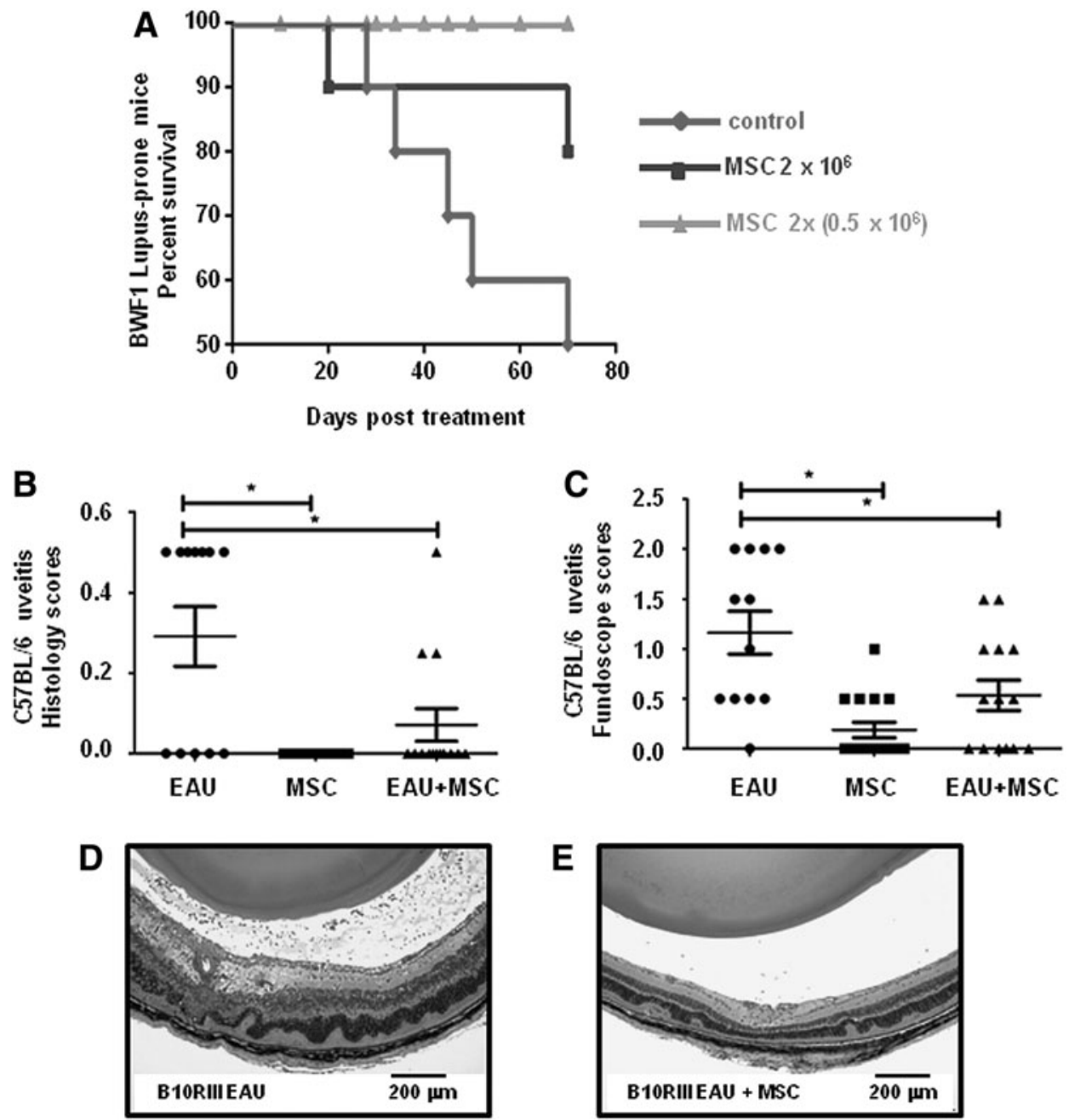

FIG. 6. Proof of principle in vivo testing for hESC-MSC therapeutic activity in two autoimmune disease mouse models. (A) Kaplan-Meier plot showing the effects of hESC-MSCs on survival of lupus-prone BWF1 mice, $n=10$ per group. MSCs were intravenously injected as either a single bolus (black line with squares) or two injections, 2 weeks apart (gray line with triangles) when BWF1 mice were 24 weeks of age. Their survival was compared with untreated control BWF1 mice (black line with diamonds). BWF1 mice have a naturally reduced lifespan (50\% median survival of $\sim 34-35$ weeks, due to lupus nephritis and kidney dysfunction). (B, C) Histology scores and fundoscopic scores of eyes from C57BL/6 mice induced with mild uveitis [experimental autoimmune uveitis (EAU), $n=6$ ], not induced with EAU but receiving hESC-MSCs on day $0(\mathrm{MSC}, n=8)$, and EAU-induced mice that also received a single injection of MSCs on day 0 (EAU + MSC, $n=7$ ). Scoring was performed at 21 days post-disease induction for both eyes from each mouse, by two independent investigators in a blinded fashion. A standard 0-4 scale was used to score severity with the higher the score indicating a more severe phenotype. (D, E) Pilot study of severe EAU induced in B10RIII mice ( $n=2$ per group). Images are histology sections of eyes from EAU B10RIII mice that did not receive any MSCs (left panel, EAU) or EAU mice which did receive MSCs (right panel, EAU + MSC). Pronounced inflammatory cell infiltration and disruption of retinal architecture is noted in the image on the left, while less inflammatory signs are noted in the eyes of an MSC-treated animal shown on the right. Scale bar $=200 \mu \mathrm{m}$. *Indicates $P<0.05$.

became highly expressed $(\geq 90 \%)$ in both MSC types (data not shown), indicating that the expression of certain cell surface markers may be subject to changes in media components. For CD24, we noted that its expression at both the RNA and protein level declined with age or on exposure to IFN $\gamma$ (data not shown). CD24 is an alternative ligand for $\mathrm{p}$ selectin, is mutated in several autoimmune disorders, and has pleiotropic roles depending on the cell type in which it is expressed [76]. Lian et al. used CD24 as a negative marker for sorting MSC progenitors $\left(\mathrm{CD} 105^{+}, \mathrm{CD} 24^{-}\right)$from $\mathrm{hESC}$ cultures [40]. The observation that a subset of our hESCMSCs maintains its expression for several passages under basal conditions is intriguing, although its significance is not entirely clear. Preliminary sorting experiments show that $\mathrm{CD} 24^{+}$and CD24- ${ }^{-}$hESC-MSCs proliferate at roughly the same rate (data not shown), yet testing the potential difference in their in vivo functionality may provide some indications as to its biological relevance. We also observed that the proliferative capacity of our hESC-MSCs is far greater than that of BM-MSCs, which is similar to what has been reported for other hESC-MSCs [41].

Previously, BM-MSCs have been observed to increase in size as they age [77]; we also observed that hESC-MSCs got larger with successive passaging, yet they tended to be 
smaller than passage-matched BM-MSCs, even at later passages. MSC function (differentiation potential, migration, and antioxidant capacity among others) is thought to decline as their growth slows down and they senesce $[78,79]$. A greater proliferative capacity and smaller size may indicate that hESC-MSC functionality can be maintained longer, enabling more therapeutic cells to be derived from a single lot of starting material than BM-MSCs.

Lastly, and unlike adult tissue-derived MSCs, a few studies have explored the therapeutic utility of hESC-MSCs in disease models. TNBS-induced experimental colitis in mice was the first model used to show that hESC-MSCs have an in vivo therapeutic function comparable to adiposeand cord-blood-derived MSCs [41]. hESC-MSCs have also been found to home to ischemic limbs [42] and enhance hematopoietic stem cell engraftment [48] in mouse models. Here, we examined the potential clinical effects of hESCMSCs in two different autoimmune disorder models, LN and EAU.

For LN, adipose- [80] and cord-blood-derived MSCs [81] have been shown to have therapeutic effects in lupus-prone BWF1 mice while another report indicates that BM-MSCs do not [82]. The MSCs that worked in this model were found to delay onset of proteinuria [80,81], increase Treg populations [80], decrease anti-dsDNA [81], and affect the balance of Th1/Th2 cells [81], leading to preservation of kidney function and an increase in lifespan [80,81]. Our cells similarly afforded a great increase in average lifespan, and investigations are underway to probe the molecular mechanisms behind this clinical improvement. Similarly, in pilot studies for both mild and severe EAU, our hESCMSCs were found to decrease the severity of disease as determined by fundoscopic imaging and histologic examination. Previous studies using murine BM-MSCs indicate that alterations in cytokine secretion and the balance between pro- and anti-inflammatory T-cell subsets (eg, Th1/ Th2, and Th17/Treg) may play a role in MSC therapeutic activity in EAU models [83-85]. A more detailed study is currently being performed to confirm these initial observations and should shed light on the mechanisms by which our hESC-MSCs may achieve clinical improvement. While research indicates that different sources of MSCs may have different properties [86,87], the data collectively presented here illustrate that hESC-MSCs are a viable alternative to adult-derived MSCs with the added benefit that they can circumvent many problems associated with adult-tissue derived MSCs. Additional studies in other animal disease models can help define the range of indications that hESC-MSCs may be useful in treating and may 1 day provide enough impetus to enable hESCs to rival adult $\mathrm{BM}$ as the preferred starting material for clinical development of MSCs.

\section{Acknowledgment}

The authors thank Lucy Vilner for cell culture assistance.

\section{Author Disclosure Statement}

E.A.K., N.A.K., G.Y., J.C., and R.L. are employees of Advanced Cell Technology, a biotechnology company engaged in stem cell and regenerative medicine research.

\section{References}

1. U.S. National Institutes of Health. www.clinicaltrials.gov (2013). Search for "mesenchymal stem cells".

2. Le Blanc K, C Tammik, K Rosendahl, E Zetterberg and O Ringden. (2003). HLA expression and immunologic properties of differentiated and undifferentiated mesenchymal stem cells. Exp Hematol 31:890-896.

3. Selmani Z, A Naji, I Zidi, B Favier, E Gaiffe, L Obert, C Borg, P Saas, P Tiberghien, et al. (2008). Human leukocyte antigen-G5 secretion by human mesenchymal stem cells is required to suppress $\mathrm{T}$ lymphocyte and natural killer function and to induce CD4 + CD25highFOXP3 + regulatory T cells. Stem Cells 26:212-222.

4. El Haddad N, R Moore, D Heathcote, M Mounayar, J Azzi, B Mfarrej, I Batal, C Ting, M Atkinson, et al. (2011). The novel role of SERPINB9 in cytotoxic protection of human mesenchymal stem cells. J Immunol 187: 2252-2260.

5. Ryan JM, F Barry, JM Murphy and BP Mahon. (2007). Interferon-gamma does not break, but promotes the immunosuppressive capacity of adult human mesenchymal stem cells. Clin Exp Immunol 149:353-363.

6. Rafei M, J Hsieh, S Fortier, M Li, S Yuan, E Birman, K Forner, MN Boivin, K Doody, et al. (2008). Mesenchymal stromal cell-derived CCL2 suppresses plasma cell immunoglobulin production via STAT3 inactivation and PAX5 induction. Blood 112:4991-4998.

7. Meisel R, A Zibert, M Laryea, U Gobel, W Daubener and D Dilloo. (2004). Human bone marrow stromal cells inhibit allogeneic T-cell responses by indoleamine 2,3dioxygenase-mediated tryptophan degradation. Blood 103: 4619-4621.

8. Hegyi B, G Kudlik, E Monostori and F Uher. (2012). Activated T-cells and pro-inflammatory cytokines differentially regulate prostaglandin E2 secretion by mesenchymal stem cells. Biochem Biophys Res Commun 419: 215-220.

9. Mougiakakos D, R Jitschin, CC Johansson, R Okita, R Kiessling and K Le Blanc. (2011). The impact of inflammatory licensing on heme oxygenase-1-mediated induction of regulatory $\mathrm{T}$ cells by human mesenchymal stem cells. Blood 117:4826-4835.

10. Ren G, L Zhang, X Zhao, G Xu, Y Zhang, AI Roberts, RC Zhao and Y Shi. (2008). Mesenchymal stem cell-mediated immunosuppression occurs via concerted action of chemokines and nitric oxide. Cell Stem Cell 2:141-150.

11. Ghannam S, J Pene, G Torcy-Moquet, C Jorgensen and $H$ Yssel. (2010). Mesenchymal stem cells inhibit human Th17 cell differentiation and function and induce a $\mathrm{T}$ regulatory cell phenotype. J Immunol 185:302-312.

12. Krampera M, S Glennie, J Dyson, D Scott, R Laylor, E Simpson and F Dazzi. (2003). Bone marrow mesenchymal stem cells inhibit the response of naive and memory antigen-specific $\mathrm{T}$ cells to their cognate peptide. Blood 101: 3722-3729.

13. Zhang W, W Ge, C Li, S You, L Liao, Q Han, W Deng and RC Zhao. (2004). Effects of mesenchymal stem cells on differentiation, maturation, and function of human monocyte-derived dendritic cells. Stem Cells Dev 13: 263-271.

14. Jiang XX, Y Zhang, B Liu, SX Zhang, Y Wu, XD Yu and $N$ Mao. (2005). Human mesenchymal stem cells inhibit differentiation and function of monocyte-derived dendritic cells. Blood 105:4120-4126. 
15. Maggini J, G Mirkin, I Bognanni, J Holmberg, IM Piazzon, I Nepomnaschy, H Costa, C Canones, S Raiden, M Vermeulen and JR Geffner. (2010). Mouse bone marrowderived mesenchymal stromal cells turn activated macrophages into a regulatory-like profile. PLoS One 5:e9252.

16. Di Nicola M, C Carlo-Stella, M Magni, M Milanesi, PD Longoni, P Matteucci, S Grisanti and AM Gianni. (2002). Human bone marrow stromal cells suppress T-lymphocyte proliferation induced by cellular or nonspecific mitogenic stimuli. Blood 99:3838-3843.

17. Aggarwal S and MF Pittenger. (2005). Human mesenchymal stem cells modulate allogeneic immune cell responses. Blood 105:1815-1822.

18. Corcione A, F Benvenuto, E Ferretti, D Giunti, V Cappiello, F Cazzanti, M Risso, F Gualandi, GL Mancardi, V Pistoia and A Uccelli. (2006). Human mesenchymal stem cells modulate B-cell functions. Blood 107:367-372.

19. Rasmusson I, K Le Blanc, B Sundberg and O Ringden. (2007). Mesenchymal stem cells stimulate antibody secretion in human B cells. Scand J Immunol 65:336-343.

20. Shin L and DA Peterson. (2013). Human mesenchymal stem cell grafts enhance normal and impaired wound healing by recruiting existing endogenous tissue stem/progenitor cells. Stem Cells Transl Med 2:33-42.

21. Semont A, C Demarquay, R Bessout, C Durand, M Benderitter and N Mathieu. (2013). Mesenchymal stem cell therapy stimulates endogenous host progenitor cells to improve colonic epithelial regeneration. PLoS One 8:e70170.

22. von Bahr L, I Batsis, G Moll, M Hagg, A Szakos, B Sundberg, M Uzunel, O Ringden and K Le Blanc. (2012). Analysis of tissues following mesenchymal stromal cell therapy in humans indicates limited long-term engraftment and no ectopic tissue formation. Stem Cells 30:1575-1578.

23. Prockop DJ. (2007). "Stemness" does not explain the repair of many tissues by mesenchymal stem/multipotent stromal cells (MSCs). Clin Pharmacol Ther 82:241-243.

24. Bieback K, S Kinzebach and M Karagianni. (2011). Translating research into clinical scale manufacturing of mesenchymal stromal cells. Stem Cells Int 2010:193519.

25. Tyndall A. (2011). Successes and failures of stem cell transplantation in autoimmune diseases. Hematology Am Soc Hematol Educ Program 2011:280-284.

26. Wagner W and AD Ho. (2007). Mesenchymal stem cell preparations-comparing apples and oranges. Stem Cell Rev 3:239-248.

27. Galipeau J. (2013). The mesenchymal stromal cells dilemma-does a negative phase III trial of random donor mesenchymal stromal cells in steroid-resistant graft-versushost disease represent a death knell or a bump in the road? Cytotherapy 15:2-8.

28. Wagner W, P Horn, M Castoldi, A Diehlmann, S Bork, R Saffrich, V Benes, J Blake, S Pfister, V Eckstein and AD Ho. (2008). Replicative senescence of mesenchymal stem cells: a continuous and organized process. PLoS One 3:e2213.

29. Rombouts WJ and RE Ploemacher. (2003). Primary murine MSC show highly efficient homing to the bone marrow but lose homing ability following culture. Leukemia 17:160 170.

30. Kyriakou C, N Rabin, A Pizzey, A Nathwani and K Yong. (2008). Factors that influence short-term homing of human bone marrow-derived mesenchymal stem cells in a xenogeneic animal model. Haematologica 93:1457-1465.

31. Li Z, C Liu, Z Xie, P Song, RC Zhao, L Guo, Z Liu and Y Wu. (2011). Epigenetic dysregulation in mesenchymal stem cell aging and spontaneous differentiation. PLoS One 6: e20526.

32. Stolzing A, E Jones, D McGonagle and A Scutt. (2008). Age-related changes in human bone marrow-derived mesenchymal stem cells: consequences for cell therapies. Mech Ageing Dev 129:163-173.

33. Li X, L Liu, D Meng, D Wang, J Zhang, D Shi, H Liu, H $\mathrm{Xu}, \mathrm{L} \mathrm{Lu}$ and L Sun. (2012). Enhanced apoptosis and senescence of bone-marrow-derived mesenchymal stem cells in patients with systemic lupus erythematosus. Stem Cells Dev 21:2387-2394.

34. Barberi T, LM Willis, ND Socci and L Studer. (2005). Derivation of multipotent mesenchymal precursors from human embryonic stem cells. PLoS Med 2:e161.

35. Trivedi $P$ and $P$ Hematti. (2007). Simultaneous generation of $\mathrm{CD} 34+$ primitive hematopoietic cells and CD73+ mesenchymal stem cells from human embryonic stem cells cocultured with murine OP9 stromal cells. Exp Hematol 35:146-154.

36. Brown SE, W Tong and PH Krebsbach. (2009). The derivation of mesenchymal stem cells from human embryonic stem cells. Cells Tissues Organs 189:256-260.

37. Karlsson C, K Emanuelsson, F Wessberg, K Kajic, MZ Axell, PS Eriksson, A Lindahl, J Hyllner and R Strehl. (2009). Human embryonic stem cell-derived mesenchymal progenitors-potential in regenerative medicine. Stem Cell Res 3:39-50.

38. Trivedi P and P Hematti. (2008). Derivation and immunological characterization of mesenchymal stromal cells from human embryonic stem cells. Exp Hematol 36:350359.

39. Raynaud CM, N Halabi, DA Elliott, J Pasquier, AG Elefanty, EG Stanley and A Rafii. (2013). Human embryonic stem cell derived mesenchymal progenitors express cardiac markers but do not form contractile cardiomyocytes. PLoS One 8:e54524.

40. Lian Q, E Lye, YK Suan, TE Khia Way, M Salto-Tellez, TM Liu, N Palanisamy, RM El Oakley, EH Lee, B Lim and SK Lim. (2007). Derivation of clinically compliant MSCs from CD105+. Stem Cells 25:425-436.

41. Sanchez L, I Gutierrez-Aranda, G Ligero, R Rubio, M Munoz-Lopez, JL Garcia-Perez, V Ramos, PJ Real, C Bueno, et al. (2011). Enrichment of human ESC-derived multipotent mesenchymal stem cells with immunosuppressive and anti-inflammatory properties capable to protect against experimental inflammatory bowel disease. Stem Cells 29:251-262.

42. Gruenloh W, A Kambal, C Sondergaard, J McGee, C Nacey, S Kalomoiris, K Pepper, S Olson, F Fierro and JA Nolta. (2011). Characterization and in vivo testing of mesenchymal stem cells derived from human embryonic stem cells. Tissue Eng Part A 17:1517-1525.

43. Olivier EN, AC Rybicki and EE Bouhassira. (2006). Differentiation of human embryonic stem cells into bipotent mesenchymal stem cells. Stem Cells 24:1914-1922.

44. Yen BL, CJ Chang, KJ Liu, YC Chen, HI Hu, CH Bai and ML Yen. (2009). Brief report-human embryonic stem cell-derived mesenchymal progenitors possess strong immunosuppressive effects toward natural killer cells as well as T lymphocytes. Stem Cells 27:451-456.

45. Wei H, G Tan, Manasi, S Qiu, G Kong, P Yong, C Koh, TH Ooi, SY Lim, et al. (2012). One-step derivation of cardiomyocytes and mesenchymal stem cells from human pluripotent stem cells. Stem Cell Res 9:87-100. 
46. Mahmood A, L Harkness, HD Schroder, BM Abdallah and M Kassem. (2010). Enhanced differentiation of human embryonic stem cells to mesenchymal progenitors by inhibition of TGF-beta/activin/nodal signaling using SB431542. J Bone Miner Res 25:1216-1233.

47. Chen YS, RA Pelekanos, RL Ellis, R Horne, EJ Wolvetang and NM Fisk. (2012). Small molecule mesengenic induction of human induced pluripotent stem cells to generate mesenchymal stem/stromal cells. Stem Cells Transl Med 1:83-95.

48. Li O, A Tormin, B Sundberg, J Hyllner, K Le Blanc and S Scheding. (2013). Human embryonic stem cell-derived mesenchymal stroma cells (hES-MSCs) engraft in vivo and support hematopoiesis without suppressing immune function: implications for off-the shelf ES-MSC therapies. PLoS One 8:e55319.

49. Klimanskaya I, Y Chung, S Becker, SJ Lu and R Lanza. (2007). Derivation of human embryonic stem cells from single blastomeres. Nat Protoc 2:1963-1972.

50. Klimanskaya I, Y Chung, S Becker, S-J Lu and R Lanza. (2006). Human embryonic stem-cell lines derived from single blastomeres. Nature 444:481-485.

51. Lu SJ, Q Feng, S Caballero, Y Chen, MA Moore, MB Grant and R Lanza. (2007). Generation of functional hemangioblasts from human embryonic stem cells. Nat Methods 4:501-509.

52. Lu SJ, C Luo, K Holton, Q Feng, Y Ivanova and R Lanza. (2008). Robust generation of hemangioblastic progenitors from human embryonic stem cells. Regen Med 3:693-704.

53. Shortman K and YJ Liu. (2002). Mouse and human dendritic cell subtypes. Nat Rev Immunol 2:151-161.

54. Wan H and M Dupasquier. (2005). Dendritic cells in vivo and in vitro. Cell Mol Immunol 2:28-35.

55. Agarwal RK and RR Caspi. (2004). Rodent models of experimental autoimmune uveitis. Methods Mol Med 102:395-419.

56. Dominici M, K Le Blanc, I Mueller, I Slaper-Cortenbach, F Marini, D Krause, R Deans, A Keating, D Prockop and E Horwitz. (2006). Minimal criteria for defining multipotent mesenchymal stromal cells. The International Society for Cellular Therapy position statement. Cytotherapy 8:315-317.

57. Roccaro AM, A Sacco, P Maiso, AK Azab, YT Tai, M Reagan, F Azab, LM Flores, F Campigotto, et al. (2013). BM mesenchymal stromal cell-derived exosomes facilitate multiple myeloma progression. J Clin Invest 123:1542-1555.

58. Chauveau C, S Remy, PJ Royer, M Hill, S Tanguy-Royer, FX Hubert, L Tesson, R Brion, G Beriou, et al. (2005). Heme oxygenase- 1 expression inhibits dendritic cell maturation and proinflammatory function but conserves IL-10 expression. Blood 106:1694-1702.

59. Francois M, R Romieu-Mourez, M Li and J Galipeau. (2012). Human MSC suppression correlates with cytokine induction of indoleamine 2,3-dioxygenase and bystander M2 macrophage differentiation. Mol Ther 20:187-195.

60. Krampera M. (2011). Mesenchymal stromal cell 'licensing': a multistep process. Leukemia 25:1408-1414.

61. Perry D, A Sang, Y Yin, YY Zheng and L Morel. (2011). Murine models of systemic lupus erythematosus. J Biomed Biotechnol 2011:271694.

62. The Jackson Laboratory (www.jax.org) 2013. Jax mice database-100008 NZBWF1/J.

63. Caspi RR. (2003). Experimental autoimmune uveoretinitis in the rat and mouse. Curr Protoc Immunol Chapter 15:Unit 15.6.
64. Choi K, M Kennedy, A Kazarov, JC Papadimitriou and G Keller. (1998). A common precursor for hematopoietic and endothelial cells. Development 125:725-732.

65. Nishikawa SI, S Nishikawa, M Hirashima, N Matsuyoshi and H Kodama. (1998). Progressive lineage analysis by cell sorting and culture identifies FLK1 + VE-cadherin + cells at a diverging point of endothelial and hemopoietic lineages. Development 125:1747-1757.

66. Lu SJ, Y Ivanova, Q Feng, C Luo and R Lanza. (2009). Hemangioblasts from human embryonic stem cells generate multilayered blood vessels with functional smooth muscle cells. Regen Med 4:37-47.

67. Grant MB, WS May, S Caballero, GA Brown, SM Guthrie, RN Mames, BJ Byrne, T Vaught, PE Spoerri, AB Peck and EW Scott. (2002). Adult hematopoietic stem cells provide functional hemangioblast activity during retinal neovascularization. Nat Med 8:607-612.

68. Lu SJ, Q Feng, JS Park, L Vida, BS Lee, M Strausbauch, PJ Wettstein, GR Honig and R Lanza. (2008). Biologic properties and enucleation of red blood cells from human embryonic stem cells. Blood 112:4475-4484.

69. Lu SJ, F Li, H Yin, Q Feng, EA Kimbrel, E Hahm, JN Thon, W Wang, JE Italiano, J Cho and R Lanza. (2011). Platelets generated from human embryonic stem cells are functional in vitro and in the microcirculation of living mice. Cell Res 21:530-545.

70. Qu X, X Liu, K Cheng, R Yang and RC Zhao. (2012). Mesenchymal stem cells inhibit Th17 cell differentiation by IL-10 secretion. Exp Hematol 40:761-770.

71. Lu LL, YJ Liu, SG Yang, QJ Zhao, X Wang, W Gong, ZB Han, ZS Xu, YX Lu, et al. (2006). Isolation and characterization of human umbilical cord mesenchymal stem cells with hematopoiesis-supportive function and other potentials. Haematologica 91:1017-1026.

72. Sze SK, DP de Kleijn, RC Lai, E Khia Way Tan, H Zhao, KS Yeo, TY Low, Q Lian, CN Lee, et al. (2007). Elucidating the secretion proteome of human embryonic stem cell-derived mesenchymal stem cells. Mol Cell Proteomics 6:1680-1689.

73. Han TH, P Jin, J Ren, S Slezak, FM Marincola and DF Stroncek. (2009). Evaluation of 3 clinical dendritic cell maturation protocols containing lipopolysaccharide and interferon-gamma. J Immunother 32:399-407.

74. Gronthos S, DM Franklin, HA Leddy, PG Robey, RW Storms and JM Gimble. (2001). Surface protein characterization of human adipose tissue-derived stromal cells. J Cell Physiol 189:54-63.

75. Psaltis PJ, S Paton, F See, A Arthur, S Martin, S Itescu, SG Worthley, S Gronthos and AC Zannettino. (2010). Enrichment for STRO-1 expression enhances the cardiovascular paracrine activity of human bone marrow-derived mesenchymal cell populations. J Cell Physiol 223:530-540.

76. Liu Y and P Zheng. (2007). CD24: a genetic checkpoint in $\mathrm{T}$ cell homeostasis and autoimmune diseases. Trends Immunol 28:315-320.

77. Lo Surdo J and SR Bauer. (2012). Quantitative approaches to detect donor and passage differences in adipogenic potential and clonogenicity in human bone marrow-derived mesenchymal stem cells. Tissue Eng Part C Methods 18:877-889.

78. Geissler S, M Textor, J Kuhnisch, D Konnig, O Klein, A Ode, T Pfitzner, J Adjaye, G Kasper and GN Duda. (2012). Functional comparison of chronological and in vitro aging: differential role of the cytoskeleton and mitochondria in mesenchymal stromal cells. PLoS One 7:e52700. 
79. Bonab MM, K Alimoghaddam, F Talebian, SH Ghaffari, A Ghavamzadeh and B Nikbin. (2006). Aging of mesenchymal stem cell in vitro. BMC Cell Biol 7:14.

80. Choi EW, IS Shin, SY Park, JH Park, JS Kim, EJ Yoon, SK Kang, JC Ra and SH Hong. (2012). Reversal of serologic, immunologic, and histologic dysfunction in mice with systemic lupus erythematosus by long-term serial adipose tissue-derived mesenchymal stem cell transplantation. Arthritis Rheum 64:243-253.

81. Chang JW, SP Hung, HH Wu, WM Wu, AH Yang, HL Tsai, LY Yang and OK Lee. (2011). Therapeutic effects of umbilical cord blood-derived mesenchymal stem cell transplantation in experimental lupus nephritis. Cell Transplant 20:245-257.

82. Youd M, C Blickarz, L Woodworth, T Touzjian, A Edling, J Tedstone, M Ruzek, R Tubo, J Kaplan and T Lodie. (2010). Allogeneic mesenchymal stem cells do not protect NZBxNZW F1 mice from developing lupus disease. Clin Exp Immunol 161:176-186.

83. Tasso R, C Ilengo, R Quarto, R Cancedda, RR Caspi and G Pennesi. (2012). Mesenchymal stem cells induce functionally active T-regulatory lymphocytes in a paracrine fashion and ameliorate experimental autoimmune uveitis. Invest Ophthalmol Vis Sci 53:786-793.

84. Li G, L Yuan, X Ren, H Nian, L Zhang, ZC Han, X Li and $X$ Zhang. (2013). The effect of mesenchymal stem cells on dynamic changes of $\mathrm{T}$ cell subsets in experimental autoimmune uveoretinitis. Clin Exp Immunol 173:28-37.

85. Zhang X, X Ren, G Li, C Jiao, L Zhang, S Zhao, J Wang, ZC Han and X Li. (2011). Mesenchymal stem cells ameliorate experimental autoimmune uveoretinitis by compre- hensive modulation of systemic autoimmunity. Invest Ophthalmol Vis Sci 52:3143-3152.

86. Rebelatto CK, AM Aguiar, MP Moretao, AC Senegaglia, P Hansen, F Barchiki, J Oliveira, J Martins, C Kuligovski, et al. (2008). Dissimilar differentiation of mesenchymal stem cells from bone marrow, umbilical cord blood, and adipose tissue. Exp Biol Med (Maywood) 233:901-913.

87. Raicevic G, M Najar, B Stamatopoulos, C De Bruyn, N Meuleman, D Bron, M Toungouz and L Lagneaux. (2011). The source of human mesenchymal stromal cells influences their TLR profile as well as their functional properties. Cell Immunol 270:207-216.

Address correspondence to: Dr. Erin A. Kimbrel Advanced Cell Technology 33 Locke Drive Marlborough, MA 01752

E-mail: ekimbrel@advancedcell.com

Dr. Robert Lanza Advanced Cell Technology 33 Locke Drive Marlborough, MA 01752

E-mail: rlanza@advancedcell.com

Received for publication November 13, 2013 Accepted after revision March 18, 2014 Prepublished on Liebert Instant Online March 20, 2014 